\title{
ÖYKÜLERİ HÜZÜNLE SARMALAMAK
}

Parvana BAYRAM*

\section{Ayşe Yılmaz BALKAN'ın Öz geçmişi}

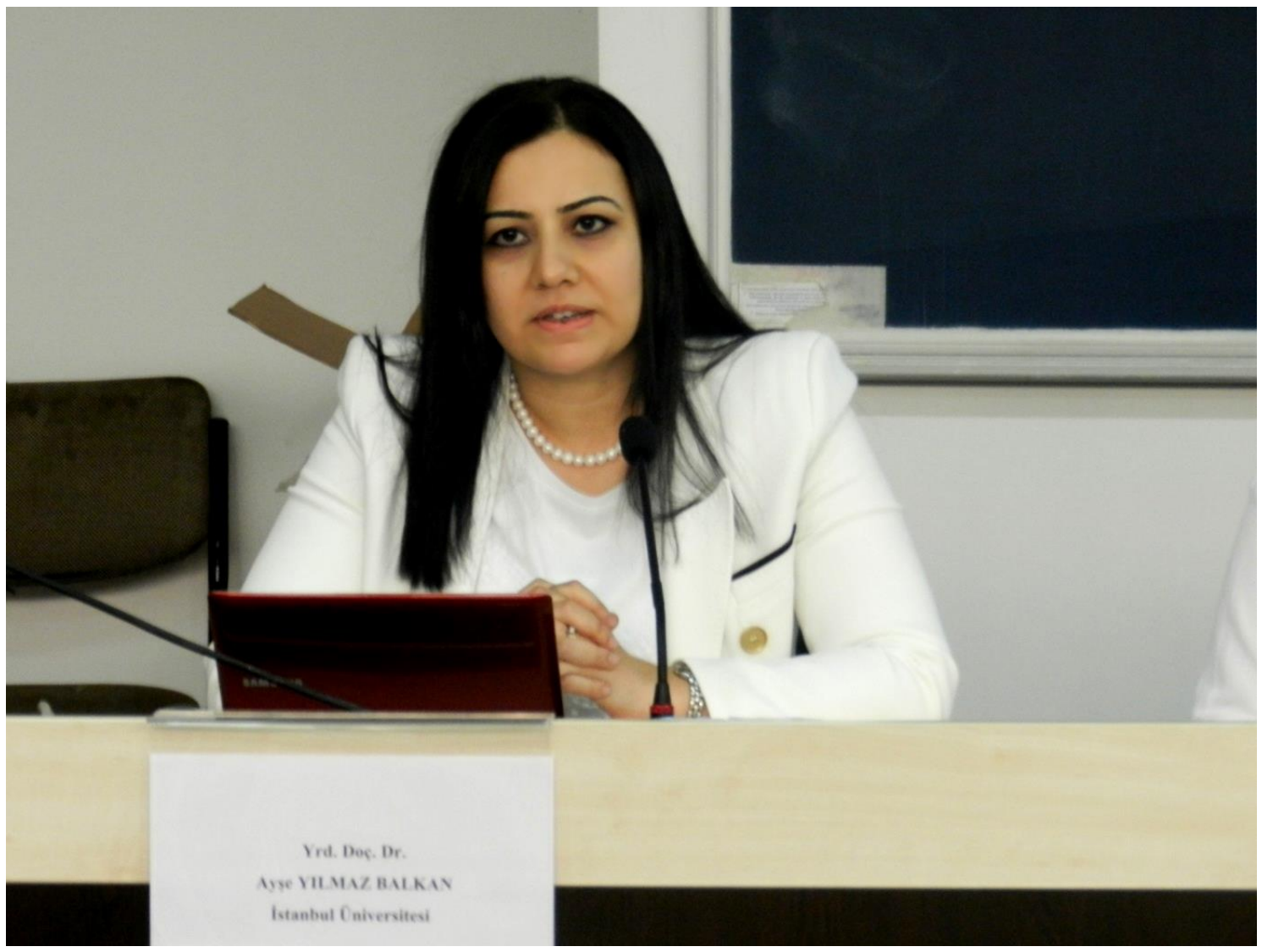

Foto 1: Yrd. Doç. Dr. Ayşe Yılmaz BALKAN

1976 y1lında İstanbul'da doğan Ayşe Yılmaz Balkan, lisans eğitimini 1994-1998 yılları arasında Marmara Üniversitesi Fen Edebiyat Fakültesi Türk Dili ve Edebiyatı Bölümünde tamamlamıştır.

Ayşe Yılmaz Balkan, yüksek lisans eğitimini Fatih Üniversitesi Türk Dili ve Edebiyatı Bölümünde Prof. Dr. Orhan Okay danışmanlığında yaptığı Mecmua-yı Edebiyye Tahlili Fihrist, İnceleme ve Seçilmiş Yazılar başlıklı teziyle 2001 yılında tamamlamıştır.

2002 yılında $M E B$ 'de Türkçe öğretmenliğine başlayan Balkan, 2004 y1lında Marmara Üniversitesi Türk Dili ve Edebiyatı Bölümünde doktora eğitimine başlamış, Doç. Dr.

\footnotetext{
* Doç. Dr.; Gazi Üniversitesi, Polatlı Fen Edebiyat Fak. Türk Dili ve Edebiyatı Bölümü, pervane32@ yahoo.com.
} 
Muhammet Gür danışmanlığında yaptığı Refik Halid Karay'ın Eserlerinde Sosyal Tenkit başlıklı teziyle 2010 yılında doktora eğitimini tamamlamıştır.

2010 yılının Kasım ayında İstanbul Üniversitesi Edebiyat Fakültesi Çağdaş Türk Lehçeleri ve Edebiyatları Bölümüne yardımcı doçent olarak atanan Balkan, hâlen üniversitedeki görevine devam etmektedir. Evli ve bir çocuk annesi olan Balkan'ın Yeni Türk Edebiyatı ve Çağdaş Türk Dünyası Edebiyatları alanında çok sayıda önemli çalışması bulunmaktadır.

\section{Ayşe Yılmaz Balkan'ın Yayınları}

\section{- Kitapları ve Kitap Bölümleri}

SÖYLEMEZ, O. ve YILMAZ, A. (2005). Anar - Bir Fırsat Bulsam. Türk Dünyası Edebiyatlarl: Roman I, 21-27. Ankara: Akçă̆ Yayıncılık.

SÖYLEMEZ, O. ve YILMAZ, A. (2005). Annaguli Nurmemmet - Nuh Tufanı. Türk Dünyasl Edebiyatları: Roman I, 241-249. Ankara: Akçağ Yayıncılık.

SÖYLEMEZ, O. ve YILMAZ, A. (2005). Elçin - Ölüm Hükmü. Türk Dünyası Edebiyatları: Roman I, 28-38. Ankara: Akçağ Yayıncılık.

SÖYLEMEZ, O. ve YILMAZ, A. (2005). Halimat Bayramuk - İki Kasım Bin Dokuz Yüz Kırk Üç. Türk Dünyası Edebiyatları: Roman I, 81-89. Ankara: Akçağ Yayıncılık.

SÖYLEMEZ, O. ve YILMAZ, A. (2005). Nur Ali Kabul - Unutulan Sahiller. Türk Dünyası Edebiyatları: Roman I, 201-208. Ankara: Akçağ Yayıncılık.

SÖYLEMEZ, O. ve YILMAZ, A. (2005). Tahavi Ahtanov - Boran. Türk Dünyası Edebiyatlart: Roman I, 125-129.Ankara: Akçağ Yayıncılık.

YILMAZ, A. (2006). Evliya Çelebi / Seyahatnâme'den Seçmeler. İstanbul: Bordo Siyah Yayınları.

YILMAZ, A. (2007). Bozkırda Yeşeren Sevda Türküleri - Aytmatov ve Eserleri Üzerine. İstanbul: Ötüken Yayınları.

SÖYLEMEZ, O. ve YILMAZ, A. (2009). Edebiyatın Misyonu. Cengiz Aytmatov, 353-369. Ankara: T.C. Kültür ve Turizm Bakanlığı Yayınları. ed. Ramazan KORKMAZ.

YILMAZ, A. (2011). Hüzne Sarılmış Öyküler. İstanbul: Ötüken Yayınları.

YILMAZ BALKAN, A. (2013). Fujiyama'da Kendini Keşfetmek. Bozkırın Oğlu: Cengiz Aytmatov, 7380. Ankara: Laçin Yayınları. ed. Ercan KÖKSAL.

\section{- Makale ve Bildirileri}

YILMAZ, A. (1998). Bir Sovyet Aydınının Trajedisi. Atatürk Üniversitesi Türkiyat Araştırmaları Enstitüsü Dergisi, 10, 295-300.

YILMAZ, A. (1998). Sovyet Rejimi Kıskacındaki İki Türk Yazarının Etkileşimi: Cengiz Aytmatov, Tahavi Ahtanov. Atatürk Üniversitesi Türkiyat Araştırmaları Enstitüsü Dergisi, 9,257-261.

YILMAZ, A. (2002). Cengiz Aytmatov'un Roman ve Hikâyelerinde Savaş ve Öksüz Çocuklar. Savaşın Çocukları: Öksüzler ve Yetimler Uluslararası Sempozyumu.

YILMAZ, A. ve SÖYLEMEZ, O. (2003). Türk Dünyası Romanlarında Hapishane ve Sürgün. Türk Dünyası Edebiyatında Hapishane ve Sürgün.

YILMAZ, A. (2004). Azeri Yazar Elçin'in Ölüm Hükmü ve Ak Deve Romanlarında Ölüm Motifinin Kullanımı. Türk Kültüründe Ölüm Uluslararast Sempozyumu. 
YILMAZ, A. (2004). Bedri Rahmi Eyüboğlu'nun Şiirlerinde Meyve Motifinin Kullanımı. Türk Kültüründe Meyve.

YILMAZ, A. (2004). Bozkırdaki Bilge: Cengiz Aytmatov. Bilge, 41.

YILMAZ, A. (2004). Cengiz Aytmatov Hayatı ve Eserleri Üzerine İncelemeler. Bilge, 40, 59-60.

YILMAZ, A. (2004). Mecmua-i Edebiye Dergisinin Özellikleri. Türk Kültürü İncelemeleri Dergisi, 11, 167-192.

YILMAZ BALKAN, A. (2011). Azerbaycanlı Şair Nigar Refibeyli'nin Şiirlerinde Sonbahar. Edebiyatta Sonbahar Alanya-Türkiye Uluslararası Sempozyumu.

YILMAZ BALKAN, A. (2011). Bedri Rahmi Eyüboğlu'nun Şiirlerinde Meyve Motifinin Kullanımı. Türk Kültürü İncelemeleri Dergisi, 25, 165-178.

YILMAZ BALKAN, A. (2011). Cengiz Aytmatov'un Gün Olur Asra Bedel Romanının Metinlerarası İlişkiler Bağlamında İncelenmesi. II. Uluslararası Türk Dili ve Edebiyatı Sempozyumu, Isparta.

YILMAZ BALKAN, A. (2011). Cihan Aktaş'ın Azize'nin Son Günü Adlı Hikâye Kitabındaki Azeri Kültürüne Ait Unsurlar. Hazar Üniversitesi Azerbaycan Dünya Edebiyatında Uluslararası Sетроzуити, Azerbaycan.

YILMAZ A. (2012). Cengiz Aytmatov'u Hatıralarının Işı̆̆ında Okumak. Uluslararası Anı Edebiyatı Sетроzуити, İstanbul-Türkiye.

YILMAZ BALKAN, A. (2012). Bahtiyar Vahapzade'nin Şiirlerinde Sevgiliye Sitem. Qafqaz Universiteti, I. Beynalxalq Baxtiyar Vahapzadə Simpoziumu, Bakü, Azerbaycan.

YILMAZ BALKAN, A. (2012). Cengiz Aytmatov'un Beyaz Gemi Romanında Metinlerarasılık. Uluslararası Cengiz Aytmatov ve Türk Uygarlı̆̆ının Rönesansı Kongresi, Bişkek, Kırgızistan.

YILMAZ BALKAN, A. (2013). Aytmatov'un Ütopyası ve Distopyası. Doğumunun Seksen Beşinci Yllinda Cengiz Aytmatov Sempozyumu.

YILMAZ BALKAN, A. (2013). Cihan Aktaş'ın Azizenin Son Günü Adlı Hikâye Kitabındaki Azerbaycan Kültürüne Ait Unsurlar. Atatürk Üniversitesi Türkiyat Araştırmalarl Enstitüsü Dergisi.

YILMAZ BALKAN, A. (2013). Hayattan Esere Cengiz Aytmatov. Turkish Studies,.

YILMAZ BALKAN, A. (2013). Refik Halid Karay'ın Ana Dilin Kullanımına Dair Görüşleri. II. Türk Dili ve Edebiyatı Kongresi, Bosna Hersek.

YILMAZ BALKAN, A. (2014). Ayaz İshaki'nin Üyge Taba (Eve Doğru) Romanı ile Cengiz Dağcı'nın O Topraklar Bizimdi Romanlarında Aslına Dönüş / Eve Dönüş. Atatürk Üniversitesi Edebiyat Fakültesi Sosyal Bilimler Dergisi, 52.

YILMAZ BALKAN, A. (2014). Cengiz Aytmatov'un Beyaz Gemi Romanı Örneğinde İnsani Değerlerin Yeniden İnşasında Edebi Eserin Fonksiyonu. İnsani Değerlerin Yeniden İnşası Sempozyumu, Erzurum.

YILMAZ BALKAN, A. (2014). Refik Halid Karay'ın Hatıraları, Mizah Yazıları ve Kroniklerinde I. Dünya Savaşı'nın İş̧lenişi. Çankırı.

\section{- Diğer Yayınları}

YILMAZ, A. (1998). Cengiz Aytmatov'da Eser Biyografi İlişkisi. Türk Edebiyatı, 299.

YILMAZ, A. (1999). Bir Aslına Dönüş Hikâyesi. Açılım (Tarih, edebiyat, kültür, sanat bülteni).

YILMAZ, A. (1999). Milli Mücadele Dönemi Anadolu Basınından Bir Örnek: Milli Gaye. Müteferrika.

YILMAZ, A. (2002). Cengiz Aytmatov'un Dünya Literatürüne Mal Ettiği Kavram: Mankurtizm. Türk Edebiyatı, 349.

YILMAZ, A. (2002). Cengiz Aytmatov'un Romanlarındaki Çağdaş Mankurtlar. Türk Edebiyatı, 350. 
YILMAZ, A. (2003). Bir Başka İstanbul'u Hatırlamak. Türk Edebiyatı, 362.

YILMAZ, A. (2003). İkiz Kavakların Türküsü. Türk Edebiyatı, 358.

YILMAZ, A. (2003). Kırlangıçlarla Söylenen Ayrılık Şarkısı. Türk Edebiyatı, 359.

YILMAZ, A. (2003). Kızıl Bir Elmaya Saklanmış Düşler. Türk Edebiyatı, 360.

YILMAZ, A. (2003). Yitik Bir İstanbul Masal1. Türk Edebiyatı, 356.

YILMAZ, A. (2004). Evrensele Doğru Cengiz Aytmatov. Cengiz Aytmatov (Doğumunun 75.Yılı Için Armă̆an). Bişkek: Kırgızistan-Türkiye Manas Üniversitesi Yayınları.

YILMAZ, A. (2005). Ayrılığı Alagözlüm'le Soluklamak. Türk Edebiyatı.

YILMAZ, A. (2005). Divan Şiirini Aşkla Okumak. Karizma, 24.

YILMAZ, A. (2008). Aytmatov Olmak. Temrin, 5.

YILMAZ, A. (2008). Beyaz Gemi’sine Kavuşan Sevdalı Yürek: Cengiz Aytmatov. Anlayış, 62.

YILMAZ, A. (2010). Yatık Emine'nin Sergüzeşti. Temrin.

YILMAZ BALKAN, A. (2014). Cengiz Dağcı'nın Seçilmiş Meleği: Regina, Kardeş Kalemler.

YILMAZ BALKAN, A. (2014). Onlar da İnsand1. Türk Edebiyatı, 486.

\section{Hüzne Sarılmış Öyküler}

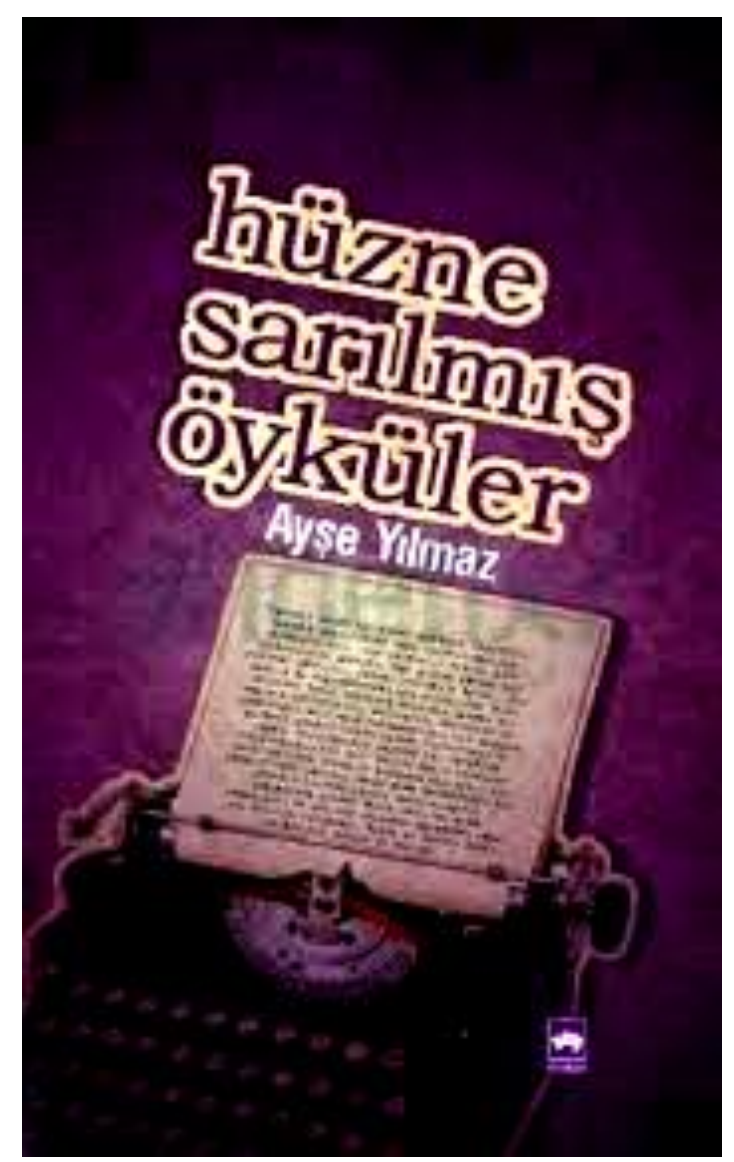

Foto 2: Hüzne Sarılmış Öyküler adlı kitabın kapak görüntüsü

Eski ve Yeni Türk Edebiyatı alanındaki klasikleşmiş çalışmalara yeni bir soluk getirebilmek için eğitirken, araştırırken düşündürmek ve eğlendirmek; bilimsel çalışmalarda 
insan unsurunu, insanın ilahî boyutunu esas alarak çeşitli yönleri ile insanı merkeze yerleştirmek ve yapılan tüm çalışmaların sırf insan için olduğunu vurgulamak gerekmektedir. Son yıllarda yapılan ilmî ve edebî çalışmalarda bu hususa dikkat edilmesi takdire şayan bir durumdur. 2011 yılının Ağustos ayında Yeni Türk Edebiyatı alanında öykü çözümlemesi ile deneme türünün başarıyla harmanlandığı bir eser yayımlandı. Eserin müellifi, 2007 yılında, Cengiz Aytmatov'un eserleri üzerine yaptığı çalışmalardan oluşan Bozkırda Yeşeren Sevda Türküleri adlı kitabıyla tanınan Yrd. Doç. Dr. Ayşe Yılmaz Balkan'dır.

Ayşe Yılmaz Balkan, Hüzne Sarılmış Öyküler adını verdiği bu mütevazı eserinde, Türkiye ve Türk dünyası edebiyatından derlenen hikâyelerden hareketle günümüz için, özellikle toplumumuzun çocuğundan kadınına, babasından annesine, gencinden sevgilisine, kedisinden köpeğine, eşeğinden ağacına kadar insanı ve çevresini, insan-tabiat ilişkisini anlatan hikâyeleri yorumlar, insanlık için geçerli olan önemli hususlara temas eder. Müellifin arka kapak yazısındaki şu ifadeleri eseri özetleyecek mahiyettedir:

Hüzne Sarılmış Öyküler'de her hâliyle insanı anlatan, insana dokunan hikâyelere yer vermeye çalışım, zira insan bir muammaysa her hâli de bir hikâyeydi elbet ve seçtiğim metinler de bunu yansıtmalıydı. Ezber bozmak istedim, az bilinen, dokunulmamış hikâyeler hakkında yazarak yahut herkesin bildiği metinlerdeki dikkatlerden kaçmış ayrıntılar üzerinde durarak. Hikâyeleri kronolojik yahut alfabetik düzene göre sıralamadım; yazarları, mensup oldukları edebî mekteplere göre de tasnif etmedim. Seçimlerimde yalnız gönlümü esas aldım, gönlümden geçtiği gibi, içimden geldiği gibi, olabildiğince kendimce oldu seçimlerim (Yılmaz, 2011: Diş Kapak).

Eseri sürükleyici kılan en önemli husus "insana en çok yakışan” hüzün duygusunun seçilen hikâyelerde bir iğne oyası titizliği ile işlenmiş olmasıdır. Gökgüvercinlerin kanatlarındaki umutları Sultanmurat ve Mirzagül'le devşirmeye çalışırken; Yatık Emine'ye ve onu bu duruma düşüren çevresine ya da küçücük Hasan'1 yabancısı olduğu gurbetlere yollayan gerideki yakınlarına kızarken; yitik İstanbul'u nafile bir çabayla ararken, ağacın bile rahatını kaçıran aşk duygusuna aşina olurken; "Dertli"nin derdiyle dertlenip, garip bir telefondaki garip sevgilinin gizemini çözmeye çalışırken, boğulan Hasan'ın ve Hasanların kurtulması ve bir daha boğulmaması için çareler ararken; göz pınarları yaşadığ1 felaketin dehşetinden ebedî olarak kuruyan üç çocuğunu kaybetmiş Ayşe kadının hayata tutunmasına şahit olurken; açlık ve sefaletle kıvranan güzel Naciye'nin mükellef bir sofra uğruna ahlaksızlığın eşiğine gelişinin ve son anda iradesini ortaya koyarak kurtuluşunun hikmetine şaşırırken hep hüzünle sarılıp sarmalar. İşte tam da bu anda bu hüzünlerin aslında bizi biz yaptığını ve kültürel birikimleri şekillendirdiği hayretle fark edilir. 
Hüzne Sarılmış Öyküler'deki hikâyeler, yazar tarafından altı ana başlık altında değerlendirilerek meşhur şair ve yazarların eserlerinden seçilmiş başlığa uygun epigraflarla okuyucunun hikâyeye hazırlık yapması sağlanır. Sıcak, samimi bir ön sözle okuyucuların gönlünü fetheden yazar, bu samimi ön sözünde "okumanın çoğalmak olduğunu" ifade eder; eserin nasıl ortaya çıktığını, hikâye ve denemeleri hangi olayların etkisi altında yazdığını şöyle açıklar:

Mademki insan bir demet hüzünden ibaretti. Mademki güzellikler dahi hüzünle sarılıp sarmalanmıştı, her yalnızlık neşeli dost sohbetlerine gebeydi, her gecede parlak bir dolunay saklıydı, yazmak lazımdı o hâlde... Bir ananın üç ciğerparesini göç yollarında telef edişinin tarif edilemez acısını; düşmüş bir kadının horlanışını, ezilişini, önlenemez acı sona doğru adım adım yaklaşmasını; bir çocuğun gurbete gönderilirken içinde birikenleri ve yağmur bulutlarının küçücük bir rüzgârla boşalmasını; bir aşkı belki, belli belirsiz hissettirilen sebepsiz sonuçsuz bir aşkı; bir yazarın sancılarını, yazar olma serüvenini; bir köpeğin itilmişliğini, çaresizliğini; dünyamızda bizden başka canlıların da yaşadığını ve aslında onlardan öğrenecek daha çok şeyimiz olduğunu... Yeter ki herkes kendi hikâyesini bulsun ve okusun...

Kitaptaki birinci başlık, Düşleri Çalınmış Çocuklar adını taşımaktadır. Burada Gökgüvercinlerin Kanatlarına Asılmış Umutlar, Gurbetin Billur Damlaları, Ödül: Birkaç Damla Gözyaşı, Sevilmek Iç̧in Randevu İsteyen Çocuk, Uykunun Dayanılmaz Ağırlı̆ğ, Islak Bir Yatağın Ürkütücülüğ̈̈ başlıkları altında altı hikâye incelenir, bu hikâyelerin edebî, sosyal ve psikolojik analizi yapılır.

Gökgüvercinlerin Kanatlarına Asılmış Umutlarda Cengiz Aytmatov'un Sultanmurat / Erken gelen Turnalar isimli hikâyesi çözümlenir, savaşa, savaş sırasındaki zorluklara bir çocuğun gözünden bakılarak günümüzün doyumsuz ve mutsuz nesilleri ile o devrin çocukları arasında oldukça isabetli mukayeseler yapılır.

Gurbetin Billur Damlaları ve Ödül: Birkaç Damla Gözyaşı başlıkları altında Refik Halit Karay'ın meşhur Eskici isimli hikâyesinin çözümlemesi etkili bir biçimde yapılır. Müellif, buradaki ikinci çözümlemeyi ders sırasında bir öğrencisine yaptırmış ve örnek olması ve devamının sağlanması amacıyla güzel bir jest olarak bu kitaba almıştır.

Sevilmek İçin Randevu İsteyen Çocuk hikâyesinde ise isimsiz ve anne sevgisine hasret bir çocuğun duygularından hareketle günümüzün de önemli meselelerinden olan çalışan annelerin iç dünyasına ışı tutulur. 
Uykunun Dayanılmaz Ağırlığı ve Islak Bir Yatağın Ürkütücülüğü başlıklı hikâyelerin kahramanları ise, sefalet içinde yaşayan, çalışmak zorunda kalan ve sömürülen Anadolu çocuklarıdır.

Eserdeki ikinci ana başlık Hüzün Devşiren Kadınlardır. Burada Türk edebiyatından kahraman olarak kadını merkeze alan Son Gözyaşı, Yatık Emine’nin Sergüzeşti, Beklemekle Tüketilen Bir Ömrün Hikâyesi, Vermeyince Mabud..., Sus Payı'nın Susturduğu Vicdanlar başlıkları altında beş hikâye incelenir.

Son Gözyaşı'nda Refik Halid Karay'ın Gözyaşı adlı hikâyesinden hareketle Balkan savaşlarında üç çocuğunu göç sırasında kaybeden bir annenin trajedisi anlatılırken, Vermeyince Mabud başlığı altında incelenen Ömer Seyfettin'in Zeytin Ekmek adlı hikâyesinde ise yine Balkan Savaşı esnasında vatanından kaçarak İstanbul'a sığınan ve kimsesiz kalan güzel Naciye'nin bir öğünlüğüne bile olsa mükellef bir sofrada yemek yiyebilmek için namusunu feda etmenin eşiğine gelmesi ibretli bir biçimde anlatılarak tahlil edilir.

Epigrafını Melih Cevdet Anday'ın Rahatı Kaçan A ğaçlar başlıklı şiirinden alan ve aşk duygusunu merkeze alan üçüncü bölümde ise Sevgilerin En Deriniyle Bakmak, Ne Seninle, Ne Sensiz, Garip Bir Telefon başlıkları altında üç hikâye incelemesi bulunmaktadır. Bu bölümde Sevgilerin En Deriniyle Bakmak başlığı altında Sevinç Çokum'un Rozalya Ana isimli hikâyesi çözümlenir. Kırım tatarlarının hayatından, yurt kavgası uğrunda mücadele eden Rozalya Ana'dan bahseden bu hikâyeden sonra Ne Seninle, Ne Sensiz başlığı altında Sabahattin Ali'nin Hasan Boğuldu adlı hikâyesi incelenir. Bu bölümdeki üçüncü eser ise Türk dünyası yazarlarından Azerbaycanlı yazar Anar'ın Ben, Sen, O, Bir de Telefon isimli hikâyesidir.

Eserin can alıcı ve hüznü doruk noktasına çıkaran bölümlerinden olan Vefakâr Dostlarımız: Hayvanlar başlığı altındaki dördüncü bölümünde incelenen üç hikâyenin başl1kları şöyledir: Gündüzünü Kaybeden Kuşun Güneşe yaktı̆̆ı Türkü, Zulmün Böylesi, İki Kader Arkadaşının Zorunlu Vedası.

İlk hikâyede martı Miho’nun Hacı İsmail adlı bir avcı tarafından kör edilişi ve Miho'nun kör olduktan sonra yavrularını arayışının dramatik hikâyesi anlatılmaktadır. Zulmün Böylesinin konusu Dertli isimli eşeğin çocuklar tarafından dövülerek, zulmedilerek öldürülüşüdür. İki Kader Arkadaşının Zorunlu Vedasında ise vatanından sürülmüş Osman'la sevgiye susamıs zavallı bir köpeğin ortak kaderlerine dayanan acıklı hikâyesi yazar tarafından çözümlenir.

Hayatı Yazarak Anlamlandırmak başlıklı beşinci bölümde ise iki yazı bulunmaktadır: Beyaz Gemisine Kavuşan Sevdalı Yürek: Cengiz Aytmatov ve Babamın Bavulundan Çıkanlar. 
$\mathrm{Bu}$ başlıklardan birincisi Cengiz Aytmatov'un ölümüne yazılmış bir nekrologdur. Babamın Bavulundan Çıkanlar başlıklı yazıda ise Nobel ödüllü yazar Orhan Pamuk'un Nobel ödülünü alırken yaptığı konuşmadan hareketle "yazmak ve yazarlık nedir, yazar kimdir?" sorularına cevap aranırken, aslında yazıyla ucundan kıyısından meşgul olan herkese önemli ipuçları da verilmektedir.

Yitik Istanbul'un Masalını Yazmak başlıklı altıncı bölümde de iki yazı yer almaktadır: Yitik Bir İstanbul Masalı ve Bir Başka İstanbul'u Hatırlamak. Bu başlıklar altında Sevinç Çokum'un ve Orhan Okay'ın İstanbul ile ilgili eserleri incelenıp ve tanıtılmıştır.

Ana başlıklardaki temel konuları sıralandığında Ayşe Yılmaz Balkan'ın mercek altına aldığ1 ve öncelik verdiği konular; ezilen, sömürülen, ihmal edilen çocuklar, savaşların yıpratıp soldurduğu, toplumun dışlayarak felakete iteklediği ve asla kendi hayallerini, umutlarını gerçekleştiremeyip başka hayatları yaşamak zorunda bıraktırdığı kadınlar, hiç bir zaman değerinden bir şey kaybetmeyen aşk duygusu, insanların zulmüne uğrayan hayvanların hikâyeleri, Türk dünyasından iki yazarın sanatı ve yitik hazineye dönüşen İstanbul ve bu şehirle ilgili eserlerdir.

İncelenen yazılardan hareketle, müellifin incelemeye aldığı hikâyelerin yazar kadrosu da tespit edebilir. Eserde Türk dünyası yazarlarından Cengiz Aytmatov ve Anar'ın birer hikâyesi incelenmiştir. Doktora tezini Refik Halid Karay üzerine yapan Yılmaz Balkan'ın kitapta da bu yazarın hikâyelerine ağırlık verdiği görülmektedir. Refik Halid Karay kitapta; Eskici, Göz Yaşı, Yatık Emine, Sus Payı ve Köpek hikâyeleriyle yer almaktadır. Refik Halid dışında Türk edebiyatından Fatma Karabıyık Barbarosoğlu, Orhan Kemal, Yaşar Kemal, Ömer Seyfettin, Sevinç Çokum, Sabahattin Ali, Cevat Şakir Kabaağaç, Hüseyin Rahmi Gürpınar birer hikâyeleriyle; Orhan Okay ve Sevinç Çokum'un İstanbul'la ilgili iki kitabının tanıtımları da yer almaktadır. Bunun dışında Orhan Pamuk'un nobel konuşması ve Cengiz Aytmatov'un ölümü üzerine yazılmış iki yazının da kitapta hikâye çözümlemeleri vardır.

Müellif, bu eserde çözümlediği hikâyeleri çağdaş araştırma teknikleri açısından biraz daha zenginleştirirse Hüzne Sarılmış Öyküler'in Mehmet Kaplan'ın Hikâye Tahlilleri tarzında yapılan en başarılı örneklerinden biri olacağı kanaatindeyiz. Hüzne Sarılmış Öyküler, Türkiye ve Türk dünyası edebiyatı üzerine yazılmış deneme ve hikâye tahlillerini okumak isteyen okuyucular, araştırmacılar, özellikle üniversite öğrencileri için başucunda bulunması gereken; öğretici, ufuk açıcı, yerine göre anne, eş, baba veya evlat olmanın; nihayetinde insan olmanın gereklerini yerine getirme bilinci kazandıran önemli bir kitaptır. Eminiz ki bu kitapta herkes kendi hikâyesini bulacak ve bu duygunun tesiriyle hayatına bir çekidüzen vermenin peşine düşecektir.

TF̂R

Uluslararası Türkçe Edebiyat Kültür Eğitim Dergisi Sayl: 4/2 2015 s. 852-859, TÜRKIYYE 